Results of the Determinations of the Mercury and Iodine in SoAPS CONTAINING MERCURIC IODIDE.

\begin{tabular}{|c|c|c|c|c|c|}
\hline Sample. & $\begin{array}{c}\text { Soap } \\
\text { taken. } \\
\text { Grams. }\end{array}$ & $\begin{array}{l}\mathrm{HgI}_{2} \text { added } \\
\text { or claimed } \\
\text { as present. } \\
\text { Per cent. }\end{array}$ & $\begin{array}{c}\mathrm{HgI}_{2} \\
\text { found. } \\
\text { Per cent. }\end{array}$ & $\begin{array}{l}\text { I (total) } \\
\text { found. } \\
\text { Per cent. }\end{array}$ & $\begin{array}{c}\text { I as } \\
\text { alkali iodide } \\
\text { (calculated). } \\
\text { Per cent. }\end{array}$ \\
\hline$\ldots \ldots$ & 10.0 & 0.83 & 0.92 & I.OO & 0.48 \\
\hline$\ldots \ldots \ldots$ & 10.0 & 0.83 & 0.72 & 0.94 & 0.54 \\
\hline$A \ldots \ldots \ldots$ & 10.0 & 0.83 & 0.85 & 1.18 & 0.71 \\
\hline$A \ldots \ldots \ldots$ & I 5.0 & 0.83 & 0.96 & I.07 & 0.54 \\
\hline $\mathrm{B} \ldots \ldots$ & 3.14 & 1.0 & I.r 3 & х. 63 & $1 . \infty O$ \\
\hline$c \ldots \ldots$ & 3.69 & 1.0 & 0.70 & 0.97 & 0.58 \\
\hline$c \ldots \ldots$ & 2.87 & 1.0 & 0.78 & 0.90 & 0.46 \\
\hline $\mathrm{D} \ldots \ldots \ldots$ & 6.39 & 1.0 & $\mathrm{I} .2 \mathrm{I}$ & 1.39 & 0.72 \\
\hline$D \ldots \ldots \ldots$ & $8.3^{8}$ & I.O & 0.94 & 1.30 & 0.78 \\
\hline$E \ldots \ldots \ldots$ & 4.33 & 0.1 & 0.1 I & 0.17 & 0.11 \\
\hline$E \ldots \ldots \ldots$ & 11.80 & O.I & 0.10 & 0.22 & 0.16 \\
\hline$E \ldots \ldots \ldots$ & 3.15 & O.I & 0.10 & 0.12 & 0.06 \\
\hline
\end{tabular}

Sample A prepared in the laboratory.

$B, C$ and $D$, different samples of the same brand of soap.

Sample E, a purchased preparation.

[CONTRIBUTION FROM THE BUREAU OF CHEMISTRY, U. S. DEPARTMENT OF AGRICULTURE, No. 6I.]

\title{
A METHOD FOR THE DETERMINATION OF BLACK ALKALI IN IRRIGATING WATERS AND SOIL EXTRACTS. ${ }^{1}$
}

By W. W, SKINNER.

Received October 28, 1905.

SUCCESSFUL irrigation in an arid region depends to a large extent upon a knowledge of the soluble salts, the so-called alkali, in both soils and the water to be applied to the soils. This is particularly true of black alkali, which is the term applied to certain salts that have a corrosive action upon plants and also have the power of dissolving the humus content of soils. It is from this last characteristic that the prefix black originated, for the humus dissolved by the alkali gives the solution a dark brown or black color, which, when collected in depressions of the soil and evaporated to dryness, produces the very characteristic black alkali spots. Black alkali may therefore be the normal carbonate or bicarbonate of any of the alkalies. As a matter of fact, however, the term has been restricted to mean the carbonate and bicarbonate of sodium. The carbonates of potas-

1 By permission of the Secretary of Agriculture. 
sium and lithium would produce a similar effect to the sodium salts, but are rarely found in sufficient quantities to warrant consideration. The term black alkali is now used by practical irrigators as synonymous with sodium carbonate and it is customary for chemists to express their results in terms of sodium carbonate when soil solutions and irrigating waters are examined for black alkali. As before stated, this is not strictly correct, as small amounts of other salts than soda may be present and estimated as such. Furthermore, the salts may be, and most generally are, present in part at least as bicarbonate. However, when a soil solution containing a bicarbonate is brought to the surface and evaporated to dryness it is quickly changed to the carbonate. The ultimate effect upon plants therefore is the same, whether the sodium salts in the original solution are in the form of carbonate or bicarbonate. The use of the term black alkali, as synonymous with sodium carbonate is believed to be warranted, for all practical purposes.

From what has been before stated it is evident that for a direct determination of the black alkali content of a solution it is necessary to remove the salts of calcium and magnesium. This is effectually accomplished by the method described below, which is a modification and adaptation of the method proposed by Hehner as a substitute for the rather unsatisfactory Clark process for determining the degree of hardness of waters. The modified method has been used by the author in the examination of several hundred samples of irrigating waters and soil extracts and has given uniformly satisfactory results from an analytical standpoint, while the conclusions drawn from the results have been confirmed by actual field observations.

SOLUTIONS REQUIRED.

(r) A standard $\mathrm{N} / 5 \mathrm{O}$ sodium carbonate solution ( $\mathrm{r}$ cc. $=$ $0.00106 \mathrm{Na}_{2} \mathrm{CO}_{3}$ ).

(2) A standard $\mathrm{N} / 50$ sulphuric acid solution (I cc. is equivalent to $0.0010 \mathrm{CaCO}_{3}$ or $\left.0.00136 \mathrm{CaSO}_{4}\right)$.

(3) Indicator, erythrosine ( $0.25 \mathrm{gram}$ to a liter of water).

(4) Chloroform.

\section{MANIPULATION.}

Two hundred cc. of the water or soil solution to be examined are transferred to a platinum or silver dish, $50 \mathrm{cc}$. to $\mathrm{I}_{50} \mathrm{cc}$. of 
standard sodium carbonate added, the quantity varying with the amounts of soluble salts of calcium and magnesium present, the smaller amount usually being sufficient, and the mixture evaporated to dryness. The residue is rubbed up with distilled water, free from carbon dioxide, ${ }^{1}$ transferred to a Ioo cc. graduated flask, made up to the mark, thoroughly shaken, stoppered and allowed to stand until clear, which usually requires from twelve to fifteen hours. When clear, 50 cc., equivalent to one-half of the original quantity of water and sodium carbonate added, are carefully removed, without disturbing the residue in bottom of the flask, and transferred to the titrating bottle. For this purpose a bottle of the best white glass without any tinge of pink, with ground glass stopper and of about $250 \mathrm{cc}$. capacity, is used. Five $\mathrm{cc}$. of chloroform and I $\mathrm{cc}$. of the erythrosine solution are added and the solution titrated with the standard acid until the color disappears. The solution should be vigorously shaken after each addition of the acid, the chloroform producing a milky appearance which makes the reading of the end-point sharp and certain.

If less sulphuric acid is required than that necessary to balance one-half of the sodium carbonate added, it is evident that some of the sodium carbonate has been used up, that is, changed by reacting with soluble salts of calcium and magnesium, and is evidence that the solution originally contained no black alkali in excess but rather an excess of the so-called permanent hardness. It is customary to express the hardness in terms of calcium carbonate or calcium sulphate. , For irrigation purposes the latter is to be preferred. Therefore the difference in cubic centimeters between the sulphuric acid required and one-half of the sodium carbonate added is multiplied by the factor 0.00136 which gives the equivalent of calcium sulphate in $100 \mathrm{cc}$. of the water. But if, on the other hand, more sulphuric acid is required than that equivalent to one-half of the sodium carbonate added, then black alkali was originally present in the solution and the difference in cubic centimeters is multiplied by the factor 0.00106 , which

${ }^{1}$ For this purpose, distilled water should be vigorously boiled until approximately one-third of the original volume is evaporated, then cooled and stoppered. An ordinary laboratory wash-bottle should not be used to transfer the residue, as the carbon dioxide from the breath of the operator is sufficient to vitiate results. 
gives the black alkali in terms of sodium carbonate in roo cc. of water.

It is necessary in all cases to use an excess of the standard sodium carbonate, as the calcium and magnesium carbonates, which are precipitated in an amorphous form, are quite soluble. The presence of the excess of sodium carbonate decreases their solubility, due to the presence of the common ion $\mathrm{CO}_{3}$.

The method is of peculiar value in the examination of irrigating waters, for not only does it show the character of a water as to black alkali, but if the examination shows a water to contain an excess of the soluble salts of calcium and magnesium, the results are scarcely less valuable, for these soluble salts under proper conditions of irrigation are an antidote for black alkali. Hence, if a soil which already contains black alkali is irrigated with water containing an excess of hardness and proper methods of applying the water are used, favorable results are to be anticipated. The application of this principle was first demonstrated, by Hilgard, with the alkali soils of California, upon which he applied gypsum as an antidote for black alkali.

SUMMARY.

(I) Black alkali is not a definite compound but may consist of the carbonates and bicarbonates of any of the alkalies.

(2) Only the alkalinity due to the carbonates and bicarbonates of the alkalies should be expressed as black alkali, and not the alkalinity due to the carbonates and bicarbonates of the alkaline earths.

(3) While not strictly correct, custom and practical considerations sanction the expression of black alkali in terms of sodium carbonate.

(4) The method described yields satisfactory results for black alkali and also for the antidote for black alkali, $i$. e., soluble salts of calcium and magnesium, which for irrigation purposes should be expressed in terms of calcium sulphate.

\section{A DELIVERY FUNNEL FOR INTRODUCING LIQUIDS UNDER INCREASED OR DIMINISHED PRESSURE.}

BY T. J. BRYAN.

Received October 25, 1905 .

THE dropping funnel has replaced the thistle tube in cases where a gradual delivery of liquids gives advantage over addi- 